\section{The threat to academic science}

Colin Norman reports from Washingtion on a study of the state of US academic research

ACADEMIC scientists in the United States have been complaining bitterly during the past few years. Declining budgets and increasing amounts of red tape are putting severe strains on the country's research system and gradually eroding the quality of basic research, they claim. Yet American science remains outstanding by any measure : total funds for research and development are expected to reach about $\$ 41,000$ million this year, and scientists from the United States walked off with every Nobel Prize awarded last year. So do the complaints have any real basis, or are they simply self-interested pleas for more money?

According to an impressively detailed and closely argued report published this week*, there is indeed plenty of cause for concern about the health of academic research in the United States. Written by two social scientists working with a grant from the National Science Foundation (NSF), the report reaches this ominous conclusion: "The discoveries that are now being made are based on research initiated many years ago, the system is operating on momentum, but there are disturbing signs that the momentum generated during World War II and for 25 years thereafter has been halted. An important national resource may be eroding and the nation is faced with the possibility that it will lose scientific and technological leadership in many fields".

The authors of the study, Bruce L. R. Smith of Columbia University and Joseph R. Karlesky of Franklin and Marshall College in Pennsylvania, base that lugubrious assessment on a number of factors which are hurting the universities in general and university science in particular. Their chief message is not that academic science is in imminent danger of collapse, but that a number of far-reaching changes are taking place in the research system. "Failure to deal adequately with the long-term adverse trends could generate a decline from which recovery will be difficult and protracted", they warn.

In particular, Smith and Karlesky suggest that the problems afflicting university research could lead to

*The State of Academic Science (Change Magazine Press, New Rochelle, New York; $\$ 5.95)$. greater stratification in the higher education system, with fewer universities conducting research of the highest quality. There could also be a weakening of the traditionally close links between research and teaching, and funding constraints could lead to less support for innovative and speculative research, they warn. But the potential changes are not all bad, for Smith and Karlesky note that in 1967 the between universities and industry, after a considerable period of arms-length relationships has begun to take root again".

The most obvious problem affecting academic research is that federal support for research and development abruptly shifted gear in the late 1960 s, moving from a period of burgeoning growth to a period in which total funding failed to keep pace with inflation. Smith and Karlesky cite figures, for example, which indicate that federal expenditures on basic research dropped by about $15 \%$ in constant dollars between 1968 and 1976. And that abrupt shift coincided with a turn for the worse in the general financial health of the universities as many sources of public and private funds began to dry up while overhead costs began to increase by leaps and bounds.

Superimposed on that trend of shrinking total support has been a marked change in the nature of federal funding for academic science. Smith and Karlesky note that in 1967, the federal government spent $\$ 1,301 \mathrm{mil}$ lion to support specific research projects in colleges and universities, but another $\$ 1,022$ million was provided in the form of general research support (block grants to institutions, graduate traineeships and grants for improving general scientific capabilities). But by 1975, that pattern had changed dramatically : support for specific projects had increased to $\$ 2,222$ million while general research support had dropped to only $\$ 567$ million. "This substantial decline in institutional funding means that universities have at their disposal less discretionary money to fill gaps, start new exploratory studies ... and meet other special and changing needs". In short, universities have lost considerable flexibility in the use of federal research funds.

A major impact of the decline in financial support has been a marked deterioration in the quality of scientific instruments and other laboratory equipment in the universities, as "a number of universities have postponed the replacement of equipment and deferred maintenance", Smith and Karlesky suggest. They cite, for example, the case of one public university in the midwest which has been unable to provide any funds for scientific instruments for the past six years, and they suggest that the problem of replacing outdated instruments and poor facilities is now facing even the most prestigious universities.

It should be noted, however, that the NSF budget for fiscal year 1978, proposed by President Ford shortly before he left office, includes some \$38 million for upgrading instruments in university laboratories. The NSF budget is, however, encountering some difficulties in Congress, and it is by no means certain that even that small relief measure will be fully approved.

A second major factor affecting the health of university research has been a marked deterioration in the academic job market for young scientists, as university expansion abruptly ceased in the early 1970s and the proportion of faculty members with tenure has increased sharply. Though there are significant differences between universities and between different fields of science, Smith and Karlesky report that the proportion of faculty members occupying tenured positions increased from $47 \%$ in 1969 to $65 \%$ in 1973 . Moreover, according to a survey conducted by NSF, the tenure ratio in 1974 varied from a low of $59.1 \%$ in physiology to a high of $80.7 \%$ in chemical engineering.

"There is a growing uneasiness that the career pipelines may be too restricted and that determinants other than excellence are increasingly controlling career patterns", Smith and Karlesky report. They suggest, moreover, that "the decline in research opportunities for young investigators will be one of the most serious threats to the momentum of university research over the next decade". One noteworthy impact of the tenure logjam is, in fact, already showing up : the proportion of young faculty members (those who have held a $\mathrm{PhD}$ for less than seven years) declined from $43 \%$ in 1968 to $27 \%$ in 1975 , and a further decline is anticipated by 1980 .

As for enrolments in graduate departments, there was a major drop in the physical sciences and engineering in the early 1970s, while enrolments in the life sciences and the social sciences continued to increase. In some institutions, Smith and Karlesky predict that the rapidly shrinking numbers of graduate students could lead to decisions to drop some PhD programmes, a move which would force a painful choice between continuing to mount a research effort in the absence of graduate students or reducing re- 
search efforts to concentrate on teaching undergraduates. Such a decoupling of research and teaching functions would represent a significant departure from the traditional university role, but Smith and Karlesky note that some university departments are already contemplating whether to continue as research centres.

One of the major findings of the study was that recent trends in funding and enrolments have been felt most keenly by less distinguished departments and by less distinguished investigators. "In contrast", Smith and Karlesky report, "the leading science departments have tended to retain their relative strength ... the downward trend has not appeared uniformly throughout all second-rank institutions, and the indicators of trouble have not always reached an advanced state. But the signs are sufficiently clear to warrant the conclusion that a very rapid deterioration in the relative position of many weaker departments could well occur in the near future".

In a sense, Smith and Karlesky note, it is "highly reassuring that our system of awarding research grants and contracts according to scientific merit appears to have achieved its aim in making certain that pre-eminent investigators are able to continue their work, and in most cases with adequate support". Nevertheless, the increased stratification in university research departments and the possibility that some second-rank institutions will drop research all together, raises a number of fundamental questions.

Although PhD programmes probably over expanded during the 1960s and "some of the research undertaken a decade ago was of less than first-rank quality", how far should the drift toward fewer and fewer outstanding research departments be allowed to proceed? Smith and Karlesky argue that "it is possible that the competitive elements in the system could be undermined if there were too few universities fully equipped for pre-eminent research. The nation would then be forced to rely on a narrow base of dominant centers".

In any case they argue that the trend "towards fewer universities and departments able to mount first-class research efforts will continue so long as federal research support remains essentially level, which is likely to be the case to some extent. Universities may be able to preserve their research missions by achieving a functional division of labor among themselves and by developing highly specialised research programs. But there is a certain minimum coverage of basic science fields that a university must undertake to retain its research vitality".

\section{0-mile zones: the threat to marine science}

As THE sixth session of the gruelling Law of the Sea Conference opened in New York last week, the National Academy of Sciences warned that the latest draft treaty could "cripple" marine scientific research. The Academy's warning, contained in a letter sent to Elliot Richardson, head of the US delegation to the conference, claimed that oceanographic research is in fact already being seriously hampered by restrictions imposed by some coastal nations.

The chief concern is that the draft treaty now under discussion (called the Revised Single Negotiating Text, in United Nations parlance) would give coastal states the right to regulate scientific research conducted within 200 miles of their shores. Since the coastal regions contain some of the most interesting oceanographic pheno. mean, such as the major currents, virtually all of the oceans' biological activity and most of the world's undersea earthquakes, the Academy is worried that the treaty could put major areas of scientific research offlimits.

The revised single negotiating text would require that the consent of a coastal state be obtained before a research project is conducted within 200 miles of its shore. Consent could be denied for research which "bears substantially on the exploration of the living and non-living resources", involves drilling, or interferes with fishing or other economic activities. In addition, the coastal state would have the power to veto publication of research results from some types of projects, and it would have the right to halt a project if it believed that the research differed from the description given in the original proposal. Such restrictions could "cripple future marine scientific research which will be critical to the survival of the oceans and mankind", the Academy stated.

The Academy is therefore urging that the draft be modified to provide the following conditions for research projects conducted outside a nation's territorial water (which will probably be 12 miles), but inside the 200 -mile 'Economic Zone':

- Freedom of research should be guaranteed except for carefully specifield and limited types of projects.

- Specific criteria should determine whether or not a project requires prior consent, and a definite procedure shculd be established for obtaining consent. The chief objective would be to ensure that no unreasonable or arbitrary restrictions are imposed.

- Freedom to publish and disseminate research results should be preserved.

In addition, the Academy recommends that the nation undertaking the research should be required to keep the coastal state fully informed of the nature, objective and schedule of a proposed project. The coastal state should also have a right to be represented in the project, and it should be given preliminary and final reports, a share in the data and samples, and assistance in interpreting the results.

To support its contention that the provisions contained in the draft treaty would seriously hamper research, the Academy cites evidence that a number of coastal states are already exercising strict controls over projects within 200 miles of their shores. In particular the Academy notes that "in the past year the records of the US National University Oceanic Laboratory System, which coordinates the activities of the academic fleet, indicate that about half of the scheduled cruises for work in waters over which other nations claim control have been cancelled because requests were denied, or have been hindered sufficiently to prevent the cruise taking place. Some requests were never acknowledged; sometimes approval came too late for the program to be successfully conducted. A.t least 18 nations were involved in one way or another in inhibiting science in this way".

In spite of the Academy's strong plea, oceanographers do not hold much hope that the final version of the Law of the Sea Treaty (if such a dacument ever emerges) will protect marine research from arbitrary or unreasonable restrictions. Coastal states sometimes claim that research vessels are used as a cover for military or commercial operations and their activities should therefore be tightly monitored and controlled. Moreover, since the oceanographic research fleet belongs almost exclusively to the developed countries, there's little immediate incentive for developing countries to grant freedom of research within their economic zones.

Colin Norman 